\title{
Electron-Beam-Induced Chromism Combined with Photo- or Thermal Reverse Reaction for Color Imaging
}

\author{
Kazuyuki Enomoto, ${ }^{\mathrm{a} \dagger}$ Yasunari Maekawa, ${ }^{\mathrm{a}^{*}}$ Sachiko Kono, ${ }^{\mathrm{b}}$ Masakazu Iwasaki, ${ }^{\mathrm{c}}$ and Tadashi Narita ${ }^{\mathrm{c}}$ \\ ${ }^{a}$ High Performance Polymer Group, Environment and Industrial Materials Research Division, \\ Quantum Beam Science Directorate, Japan Atomic Energy Agency (JAEA) \\ 1233 Watanuki, Takasaki, Gunma 370-1292, Japan \\ ${ }^{b}$ Department of Applied Chemistry, Faculty of Engineering, Saitama Institute of Technology, \\ 1690 Fusaiji, Fukaya, Saitama 369-0293, Japan \\ ${ }^{c}$ Department of Applied Chemistry, Graduate School of Engineering, \\ Saitama Institute of Technology, 1690 Fusaiji, Fukaya, Saitama 369-0293, Japan \\ ${ }^{+}$Current address: The Institute of Science and Industrial Research, Osaka University \\ E-mail: maekawa.yasunari@jaea.go.jp
}

Reversible color imaging on polymer films with a spiropyran $\left(\mathbf{S P}-\mathbf{N O}_{2}\right)$ or a diarylethene $(\mathbf{D E})$ has been examined by electron-beam (EB) induced chromism combined with a photo- or thermal reverse reaction. Colorless SP-NO $\mathbf{N}_{2}$ in a poly(methyl methacrylate) (PMMA) film transformed into red-colored zwitterionic merocyanine $\left(\mathbf{M C}-\mathbf{N O}_{2}\right)$, which subsequently converted to the original $\mathbf{S P}-\mathrm{NO}_{2}$ via thermal treatment. After six time repetition of the reaction cycle, the absorption intensity of $\mathbf{M C}-\mathbf{N O}_{2}$ decreased to $56 \%$ of the initial level. The decrease was attributed to the formation of a protonated $\mathbf{M C}$-form $\left(\mathbf{M C}-\mathbf{H}^{+}\right)$via the reaction of MC-NO ${ }_{2}$ with an acid generated by EB-radiolysis of PMMA. Contrary to thermal treatment in the polymer films containing SP-NO $\mathbf{N}_{2}$, a photo reverse reaction could be applied for EB-induced color imaging using DE in the polymer films, where the thermally stable colored close-form of $\mathbf{D E}\left(\mathbf{D E}_{\mathbf{C l}}\right)$ obtained by an EB-induced reaction can be converted to the original colorless open-form $\left(\mathbf{D E}_{\mathbf{O p}}\right)$ via photoreaction. The matrix effect of poly(BFP-alt-DOX) was observed with good efficiency of color formation and higher fatigue resistance of DE than those in PSt and PMMA matrices. The color imaging of these films was performed by electron beam direct writing to form 100-1000 nm square and line/space (L/S) patterns. The color images of $5 \mu \mathrm{m}$ square patterns were produced in the PMMA film containing $\mathbf{S P - N O _ { 2 }}$ with a dose of $100 \mu \mathrm{C} \mathrm{cm}$; ; the images could be faded upon the thermal treatment. The poly(BFP-alt-DOX) film containing DE yielded clear color imaging of $100 \mathrm{~nm} \mathrm{~L} / \mathrm{S}$ patterns with a dose of $200 \mu \mathrm{C} \mathrm{cm}^{-2}$. Subsequently, the patterns bleached upon the irradiation of visible light of $>430 \mathrm{~nm}$. It is noted that these reactions are the first example for reversible transformation of color imaging induced by EB radiation together with heat or light treatment.

Keywords: Electron-beam; Chromic Dye; Color Imaging.

\section{Introduction}

Electron beam direct writing (EBDW) technique now enables a resolution limit down to sub- $10 \mathrm{~nm}$, which would not be achieved by light, and thus should be applicable to high-density recording devices. ${ }^{1}$ The major requirement for $\mathrm{EB}$ recording devices is that EB-induced chemical changes provide optical or reflective-index differentiation between the exposed and unexposed regions. We previously reported that polymer films with acid-responsive chromic molecules and acid generators were well acted as an electron beam-induced color imaging system. The
EBDW on the acid-chromic polymer films yielded clear color imaging of 100-200 $\mathrm{nm}$ line/space $(\mathrm{L} / \mathrm{S})$

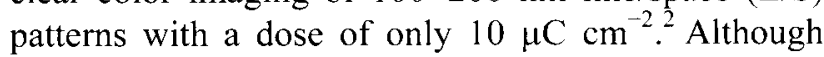
design and search for highly EB-sensitive materials are required for realizing such devices, little is known of the EB radiolysis of potential materials. ${ }^{3}$

Photochromism is photo-induced reversible isomerization of chemical species between two forms having different absorption spectra. The fast change in properties arising from the chemical-bond reconstruction via photo-excitation has been attracting 
much attention from the viewpoint of both fundamental phenomena and application to optoelectronic devices such as rewritable optical memory and switches. ${ }^{1 \mathrm{f}, 4}$ The reversible transformation of typical photochromic compounds, such as azobenzene, spiropyran, spirooxazine, and diarylethene, takes place thermally and/or photochemically. ${ }^{5}$ A data recording and de-recording system in optical memory is consisted of an each chromic dye dispersed in the transparent matrix such as poly(methyl methacrylate) (PMMA) and polycarbonate (PC). ${ }^{6}$ If EBDW technique with a beam size of $10 \mathrm{~nm}$ is applied for data-recording of optoelectronic devices, the density of memory extremely increases by several orders of magnitude. ${ }^{7}$

Thus, herein we propose EB-induced color imaging systems that show reversible transformation of chemical species between two isomers with EB irradiation and heat (or light). Spiropyran (SP-NO $\left.\mathbf{N O}_{2}\right)$ and diarylethene (DE) were employed here as photochromic dye molecules. One of the major problems to utilize the focused EB for the color imaging is low radiation resistance (mainly degradation) of matrix materials such as PMMA and PC. ${ }^{8}$ The fluorinated polymer prepared by radiationinduced polyaddition of bis( $\alpha$-trifluoromethyl- $\beta, \beta$ difluorovinyl) terephthalate with 1,4-dioxane, poly(BFP-alt-DOX), has higher radiation resistance, compared with typical degradation polymers such as PMMA and polystyrene (PSt), as shown in Scheme 1. Thus, we also investigated the matrix effect of poly(BFP-alt-DOX) on the above color imaging system compared with that of conventional polymers such as PSt and PMMA.

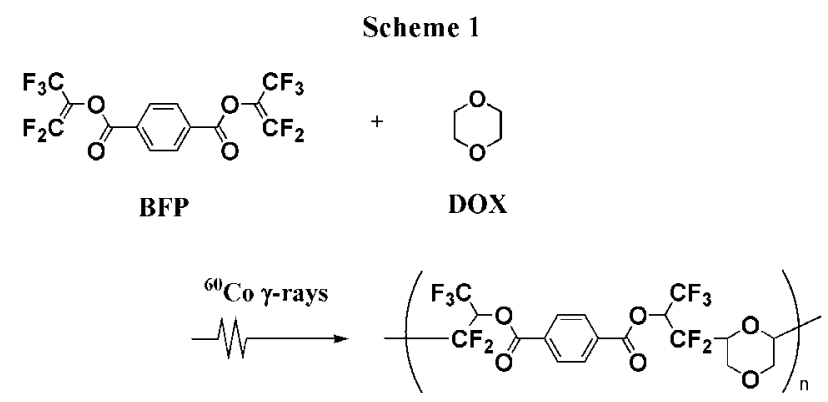

poly(BFP-alt-DOX)

\section{Experimental}

Materials. 1',3',3'-Trimethyl-6-nitrospiro[1(2H)benzopyran-2,2'-indoline] (SP-NO $\mathbf{N O}_{\mathbf{2}}$ ) was purchased from Aldrich and used as received. 1,2-Bis[2-methyl benzo[b]thiophen-3-yl]3,3,4,4,5,5-hexafluoro-1-cyclo pentene (DE) was purchased from TCI and used as received. Poly(methyl methacrylate) (PMMA) (Aldrich; $M_{\mathrm{w}}$ 15000), and polystyrene (PSt) (Scientific Polymer Products, Inc.; $M_{\mathrm{w}}$ 45000) were purified by reprecipitation from dichloromethane solution (5 wt.-\%) to a large excess amount of methanol, and then dried in vacuo. Poly(BFP-altDOX) was prepared by the $\gamma$-rays-induced polyaddition of bis( $\alpha$-trifluoro-methyl- $\beta$, $\beta$-difluorovinyl) terephthalate (BFP) with 1,4-dioxane (DOX) and purified according to our previous article $\left(M_{\mathrm{n}}=\right.$ 10600). ${ }^{9}$ Triphenylsulfonium trifluoromethanesulfonate (TPS-Tf) was purchased from Toyo Gosei Co., Ltd. and recrystallized from methanol and ethyl acetate. Cyclohexanone and 2-ethoxyethanol were supplied by Wako Pure Chemical Industries, Ltd. and used as received.

Instruments. UV-visible spectra were measured with a Hitachi U-3210 spectrophotometer. Film thickness was measured using a Mitsutoyo SURFTEST SV-600 surface profiler. Visible light illumination was conducted on an USHIO optical system with a high-pressure mercury lamp (SHUI500XQ) as a light source. The light was filtered before injecting perpendicularly on a film surface. A water cylindrical glass container with $10 \mathrm{~cm}$ in length was used for cutting off the infrared to avoid heating of the film. Color glass filter, Y-43 (Asahi Technoglass), was used for controlling the illumination wavelengths.

Preparation of polymer films. Solutions containing matrix polymers, poly(BFP-alt-DOX), PSt, and PMMA, and 5 wt.-\% of SP-NO $\mathbf{N O}_{2}$ or $8 \mathrm{wt}$. $\%$ of DE (relative to polymer weight) in cyclohexanone/ 2-ethoxyethanol $(2: 1(\mathrm{w} / \mathrm{w}))$ were passed through a $0.20 \mu \mathrm{m}$ filter. The solutions obtained were spin-coated onto quartz or silicon substrates followed by pre-bake at $90{ }^{\circ} \mathrm{C}$ for 3 min on an Iuch P-DHP hot plate. The film thickness was controlled by changing solution concentration (15-30 wt.-\%) and spinning speed (1800-3000 rpm) with a Mikasa Spincoater 1H-D7.

EB irradiation. The polymer films containing SP-NO $\mathbf{N O}_{2}$ or DE, which were covered with Kapton film (12 $\mu \mathrm{m}$ thickness) and placed on water-cooled cupper metal plates, were irradiated with $\mathrm{EB}$ of $1 \mathrm{MeV}$ and $0.5 \mathrm{~mA}$ in an atmosphere using a Cascade Type Electron Accelerator (Dynamitron) at JAEA, Takasaki. The changes in absorption spectra of exposed films were measured by UV-visible spectra.

EBDW. The nanoscopic color imaging of the polymer film containing $\mathbf{S P}-\mathbf{N O}_{2}$ or $\mathbf{D E}$ was conducted with a raster scanning EB, using the JSM-5310W Tokyo Technology Beam Draw System. The accelerating voltage of the incident electron beam was kept at $20 \mathrm{keV}$. The beam diameter was $50 \mathrm{~nm}$ with a probe current of 200 pA. The probe current was calibrated by using a Faraday cup before and after experiments. Scanning color images were acquired using a KEYENCE VK-8500 digital microscope and using a Lasertec 1LM21H confocal scanning laser microscope. 


\section{Results and Discussion}

3-1. EB-induced reactions of spiropyran

The progress of the EB-induced reaction of SP-NO $\mathbf{N}_{2}$ in PMMA films on a quartz plate was monitored using UV-vis spectroscopy because the similar films exhibited a reversible phenomenon involving photo-induced changes in the visible absorption region. Figure 1 shows changes in the UV-vis spectra of the PMMA films containing SP-NO ${ }_{2}$ with 5 wt.-\% of the polymer with irradiation doses in the range of $0-200 \mu \mathrm{C} \mathrm{cm}^{-2}$. The unexposed film has the absorption in an UV region with absorption edge at around $400 \mathrm{~nm}$ (only UV region). Upon EB-irradiation, the PMMA film containing SP-NO ${ }_{2}$ showed an absorption band at $\lambda_{\max }=552 \mathrm{~nm}$, assigned to merocyanine (MC-NO $\mathbf{N}_{2}$ ), which has a red-colored zwitterionic open-form. ${ }^{10}$ The new band increased gradually with increasing an irradiation dose with isosbestic points at $287 \mathrm{~nm}$ and $356 \mathrm{~nm}$ during EB-irradiation in the spectrum. The maximum absorption intensity was $0.04 \mu^{-1}$ with a dose of 200 $\mu \mathrm{C} \mathrm{cm}^{-2}$.

Figure 2 shows changes in UV-vis absorption spectra of the PMMA film containing SP-NO $\mathbf{N O}_{2}$ with 5 wt.-\% of the polymer by EB irradiation with a dose of $100 \mu \mathrm{C} \mathrm{cm}{ }^{-2}$ and subsequent thermal treatment at $90{ }^{\circ} \mathrm{C}$ for $30 \mathrm{~s}$; the chromic reaction between $\mathbf{S P}-\mathbf{N O}_{2}$ and $\mathbf{M C}-\mathrm{NO}_{2}$ isomers was depicted in Scheme 2. Upon EB-irradiation, the PMMA film containing SP-NO $\mathbf{N}_{2}$ exhibited a new absorption peak at $\lambda_{\max }=$ $552 \mathrm{~nm}$, corresponding to red color with a dose of 100 $\mu \mathrm{C} \mathrm{cm}^{-2}$; then, the newly generated absorption band (MC-NO $\mathbf{N}_{2}$ ) disappeared upon the thermal treatment. It is obvious that $\mathbf{S P}-\mathbf{N O}_{2}$ molecules in the PMMA film reversibly transform between colorless $\mathbf{S P}-\mathbf{N O}_{2}$ and colored $\mathbf{M C}-\mathrm{NO}_{2}$ with $\mathrm{EB}$ and thermal reactions, respectively. The absorption intensity of irradiated and thermally treated films was plotted at an each chromic cycle in Figure 2, Inset. The absorbance of the colored MC form at 552nm decreased with

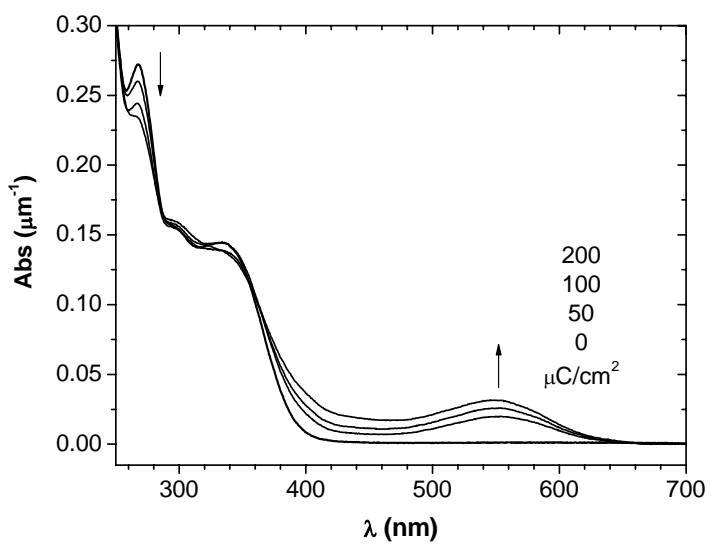

Figure 1. UV-vis spectra of the PMMA films containing SP-NO $\mathbf{N O}_{2}$ with 5 wt.-\% of the polymer with irradiation doses in the range of $0-200 \mu \mathrm{C} \mathrm{cm}^{-2}$.
Scheme 2
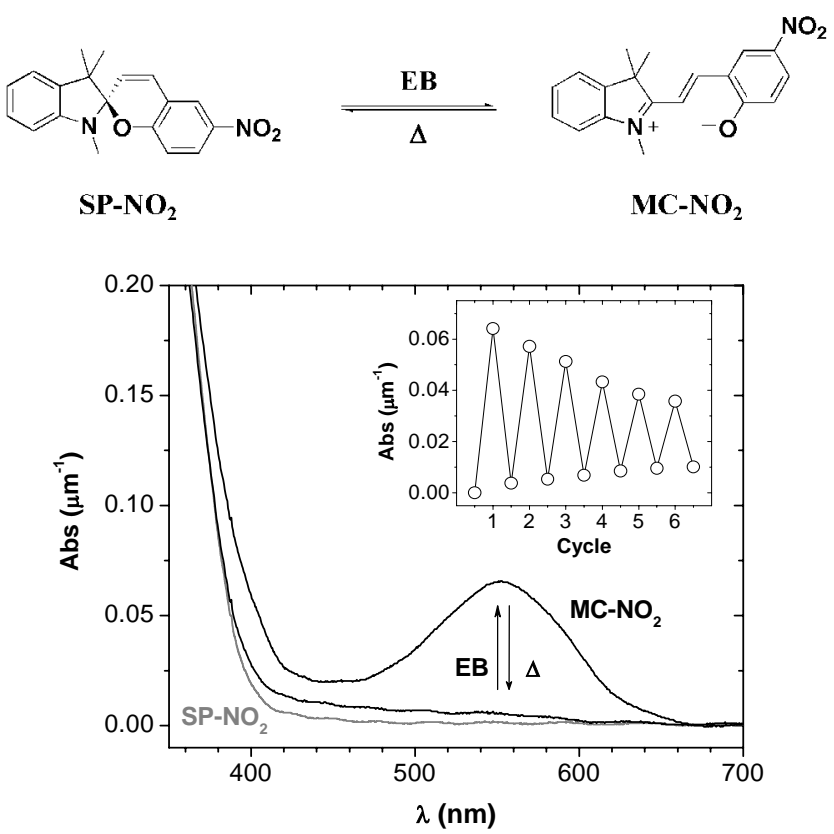

Figure 2. UV-vis spectral changes of the PMMA film containing SP-NO $\mathbf{N O}_{2}$ upon the chromic reactions with EB irradiation $\left(100 \mu \mathrm{C} \mathrm{cm}^{-2}\right)$ and thermal treatment $\left(90{ }^{\circ} \mathrm{C}\right.$, $30 \mathrm{~s})$. Inset figure: the plot of absorption intensitys of irradiated and thermally treated films monitored at 552 $\mathrm{nm}$ at an each coloration/ decoloration cycle.

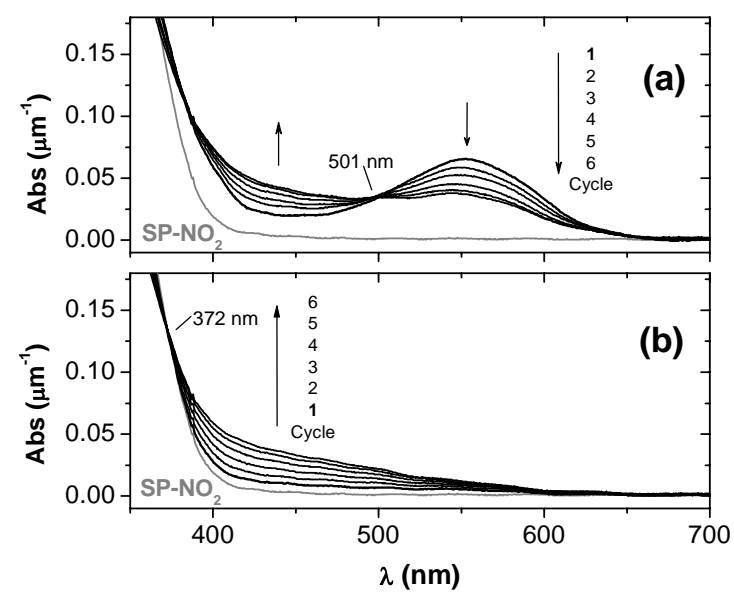

Figure 3. UV-vis spectral changes of the PMMA film containing $\mathbf{S P}-\mathbf{N O}_{2}$ upon the chromic cycles with (a) after EB irradiation $\left(100 \mu \mathrm{C} \mathrm{cm}{ }^{-2}\right)$ and (b) thermal treatment $\left(90^{\circ} \mathrm{C}, 30 \mathrm{~s}\right)$.

increasing cycle number: at six cycles, the absorbance decreased to $56 \%$ of the initial level. Figure 3 shows the UV-vis spectra of the PMMA film containing SP-NO ${ }_{2}$ after EB irradiation (Figure 3a) and thermal treatment (Figure $3 \mathrm{~b}$ ) at each $\mathrm{EB} /$ thermal chromic cycle. Both spectra were changed with isosbestic points at $501 \mathrm{~nm}$ and $372 \mathrm{~nm}$. One possible explanation for both spectral changes to show the isosbestic points is that the $\mathrm{EB} /$ thermal chromic cycles

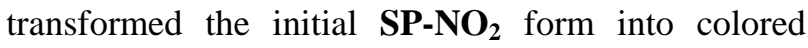


MC-NO $\mathbf{N}_{2}$ with a slight amount of a single by-product due to a side reaction.

The by-product with absorption band at around $440 \mathrm{~nm}$ (Figure 3b) is probably attributed to the protonated form $\left(\mathbf{M C}-\mathbf{H}^{+}\right)$of the zwitterionic MC open-form by comparing the absorption band with the photolytic product in acidic solutions. ${ }^{11}$ In order to confirm the formation of $\mathbf{M C}-\mathbf{H}^{+}$, PMMA films containing the same amount of $\mathbf{S P}-\mathbf{N O}_{2}$ with extra TPS-Tf, which is a highly EB-sensitive material producing a strong acid (Scheme 3), ${ }^{12}$ was irradiated. The acid generated in the film by EB induced reaction of TPS-Tf should bind with $\mathbf{M C}-\mathbf{N O}_{2}$ to form the protonated $\mathbf{M C}-\mathbf{H}^{+}$form.

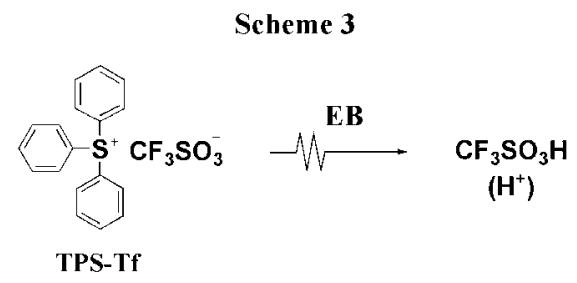

Figure 4 shows the UV-vis spectra of the PMMA film containing SP-NO $\mathbf{N O}_{2}$ and TPS-Tf as an acid generator with doses up to $300 \mu \mathrm{C} \mathrm{cm}$. The intensity of the absorption band around $440 \mathrm{~nm}$ gradually increased with increasing irradiation doses, as observed in Figure 3b. MC-NO $\mathbf{O}_{\mathbf{2}}$ is trapped with the acid $\left(\mathrm{H}^{+}\right)$generated from TPS-Tf immediately to give MC- $\mathbf{H}^{+}$. The acid, therefore, acts as a trapping agent of $\mathbf{M C}-\mathrm{NO}_{2}$ (Scheme 4). In order to examine the amounts of acid generated from PMMA upon EB irradiation, the PMMA film containing 3',6'-bis-
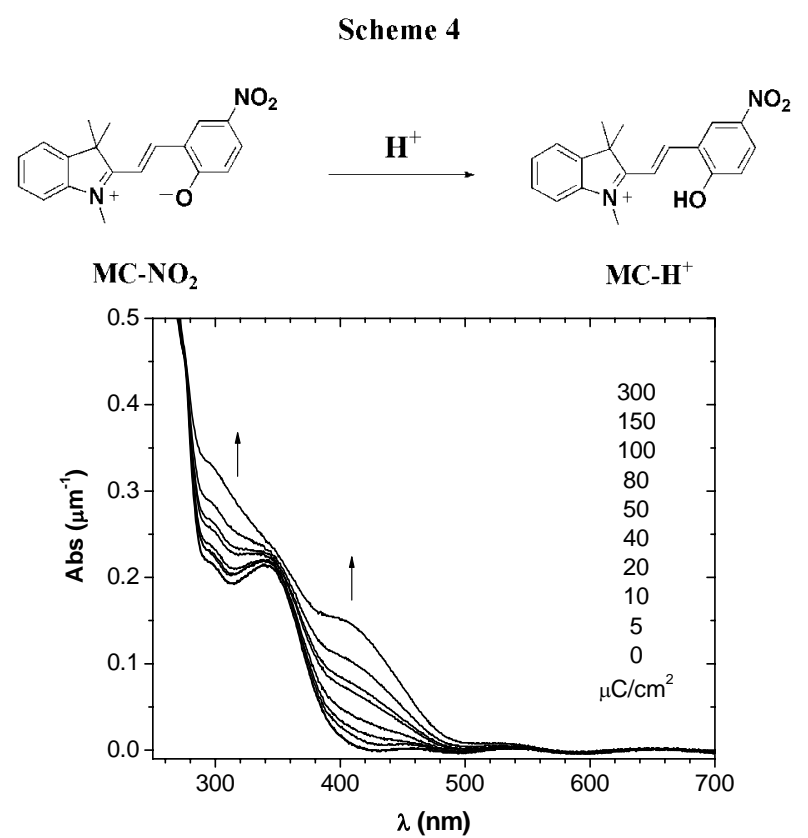

Figure 4. UV-vis spectral changes of the PMMA film containing SP-NO $\mathbf{N O}_{2}$ and TPS-Tf as an acid generator with a dose in the range of $0-300 \mu \mathrm{C}$ (diethylamino)fluoran (rhodamine $\mathrm{B}$ base), which undergoes a $\gamma$-lactone ring opening reaction to give the protonated rhodamine with absorption band at $\lambda_{\max }$ $=560 \mathrm{~nm}$, was irradiated under the same conditions. ${ }^{2,13}$ The PMMA film containing rhodamine with 1 wt.- $\%$ of the polymer was irradiated with a dose of $100 \mu \mathrm{C} \mathrm{cm}^{-2}$. The intense absorption at around $560 \mathrm{~nm}$ was observed, strongly indicating the acid generation from EB-radiolysis of the PMMA matrix. Furthermore, the acid generation from the radiolysis of ethyl acetate (AcOEt), which seems to be an analog of a PMMA monomer repeating unit, is well established. ${ }^{14}$ The initial products in the radiolysis of AcOEt are the AcOEt cation and the electron (e). The AcOEt cation subsequently converts to AcOEt radical and an acid $\left(\mathrm{H}^{+}\right)$, as shown in reactions 1 and 2, respectively.

$$
\begin{aligned}
& \mathrm{AcOEt} \rightarrow \mathrm{AcOEt}^{+}+\mathrm{e}^{-} \\
& \mathrm{AcOEt}^{+} \rightarrow \mathrm{AcOEt}^{-}+\mathrm{H}^{+}
\end{aligned}
$$

According to the above results, $\mathbf{M C}-\mathbf{H}^{+}$at $\lambda_{\max }=460$ $\mathrm{nm}$ generates in the protonation of zwitterionic MC (open-form) with the acid $\left(\mathrm{H}^{+}\right)$resulting from EB-radiolysis of the PMMA matrix.

The EB-induced chromic reactions of $\mathbf{S P}-\mathbf{N O}_{2}$ in the PMMA matrix can be formulated by a mechanism shown in Scheme 5. SP-NO $\mathbf{N O}_{2}$ primarily leads to upper or the lowest excited states of $\mathbf{S P}-\mathbf{N O}_{2}$ by direct excitation or energy transfer from matrix polymers, followed by transformation into zwitterionic MC-NO $\mathbf{O}_{2}$; in the absent of acid, $\mathbf{M C}-\mathbf{N O}_{2}$ reverts

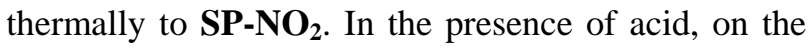
other hand, $\mathbf{M C}-\mathbf{N O}_{2}$ reacts with the acid generated by EB-radiolysis of the PMMA matrix, giving the protonated $\mathbf{M C}-\mathbf{H}^{+}$form.

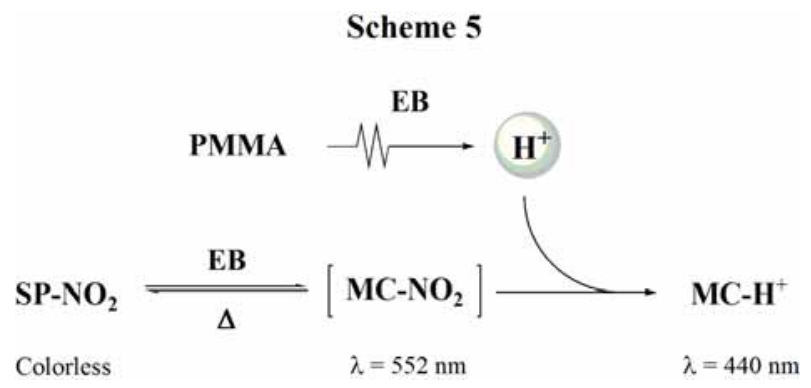

3-2. EB-induced reactions of diarylethene.

Contrary to thermal treatment for the reverse reaction in the polymer films containing $\mathbf{S P}-\mathbf{N O}_{2}$, a photo reverse reaction was applied for nanoscopic EB-induced color imaging using diarylethene (DE) in polymer films because it is well known that colorless open-form $\left(\mathbf{D E}_{\mathbf{O p}}\right)$ and a thermally stable colored close-form $\left(\mathbf{D E}_{\mathbf{C l}}\right)$ can be converted to each other via 


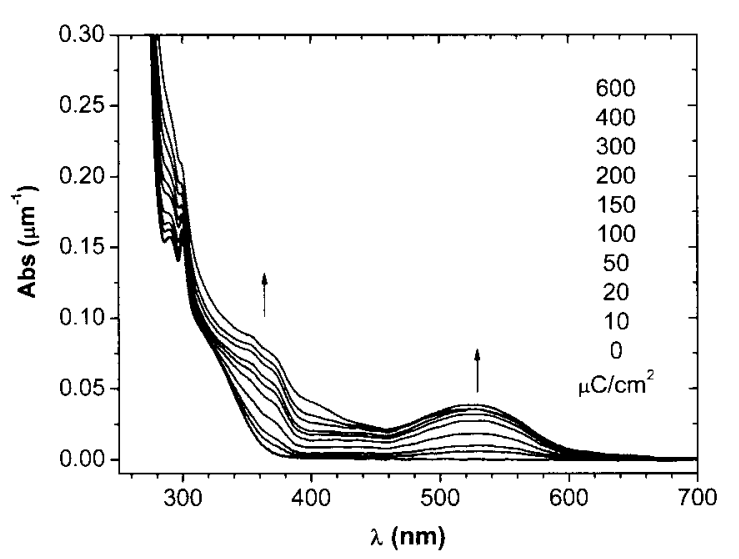

Figure 5. UV-vis spectral changes of the PSt films containing $\mathbf{D E}_{\mathbf{O}}$ with $8 \mathrm{wt}$. $\%$ of the polymer with a dose in the range of $0-600 \mu \mathrm{C} \mathrm{cm}^{-2}$.

photoreactions with different wavelengths light. ${ }^{\text {If }}$

Figure 5 shows changes in UV-vis absorption spectra of the PSt film containing $\mathbf{D E}_{\text {Op }}$ with $8 \mathrm{wt} . \mathrm{w}$ of the polymer during irradiation doses up to $600 \mu \mathrm{C}$ $\mathrm{cm}^{-2}$. Upon EB-irradiation, the PSt film containing $\mathbf{D E}_{\text {Op }}$ showed a new absorption band at $\lambda_{\max }=525 \mathrm{~nm}$, which assigned to $\mathbf{D E}_{\mathbf{C l}}$. ${ }^{\text {If }}$ The new band gradually increased with the increases of irradiation doses and then saturated at absorption intensity of $0.037 \mu \mathrm{m}^{-1}$ with a dose of $300 \mu \mathrm{C} \mathrm{cm}^{-2}$. Figure 6 shows changes in UV-vis absorption spectra of the PSt film containing $\mathbf{D E}_{\boldsymbol{O}}$ upon alternating irradiation with $\mathrm{EB}$ and $>430 \mathrm{~nm}$ light. Upon EB irradiation, the PSt film containing $\mathbf{D E} \mathbf{E}_{\mathrm{Op}}$ exhibited a red color with a dose of $100 \mu \mathrm{C} \mathrm{cm}$; the film became colorless upon the subsequent irradiation of visible light of $>430 \mathrm{~nm}$ for $1 \mathrm{~min}$. The EB/photo chromic cycle is repeated eight times. As shown in Figure 6, Inset, changes in absorption intensity of the colored $\mathbf{M C}$-form after EB irradiation decreased with increasing cycle numbers: the absorption intensity at eight cycles was $59 \%$ of that observed at the first cycle. The low durability of DE doped in PSt film may accounts for the formation of by-product due to a side reaction induced by the EB-radiolysis of PSt as well as PMMA (vide ante).

Figure 7 shows UV-vis absorption spectra of the PSt film containing $\mathbf{D E}_{\mathbf{O} p}$ at each alternating irradiation cycle with $\mathrm{EB}\left(100 \mu \mathrm{C} \mathrm{cm}^{-2}\right)$ and $>430 \mathrm{~nm}$ light for $1 \mathrm{~min}$; (a) after EB irradiation and (b) after visible light irradiation. The absorption bands at $\lambda_{\max }$ $=525 \mathrm{~nm}$ and at around $370 \mathrm{~nm}$, which were separated via an isosbestic point at $460 \mathrm{~nm}$, decreased and increased with increasing cycle numbers, as shown in Figure 7a. The absorption band at around $370 \mathrm{~nm}$ in the film after visible light exposure also increased with increasing cycle numbers (Figure $7 b$ ). The presence of isosbestic points indicates that a slight amount of a single by-product gradually accumulated during the EB/photo chromic cycles even thought, at this moment, the by-product possessing
Scheme 6
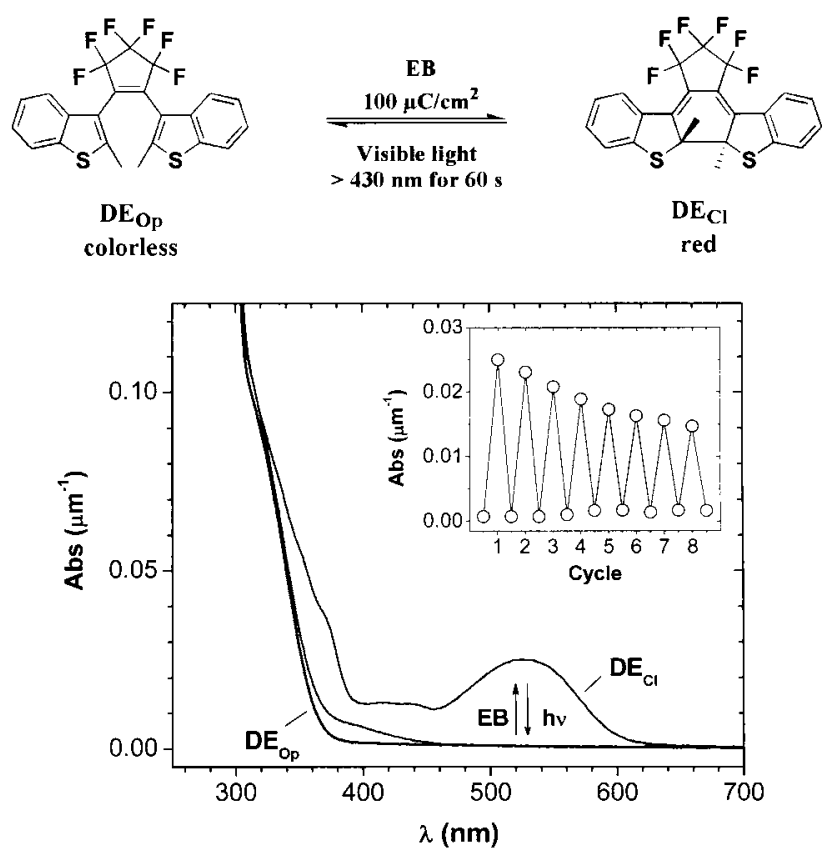

Figure 6. UV-vis spectral changes of the PSt film containing $\mathbf{D E}_{\mathbf{O p}}$ upon alternating irradiation with EB $(100 \mu \mathrm{C} \mathrm{cm}$ ) and light $(>430 \mathrm{~nm}, 1 \mathrm{~min})$. Inset figure: the plot of absorption intensity of $E B$ and photo irradiated films monitored at $525 \mathrm{~nm}$ at each coloration/decoloration cycle.

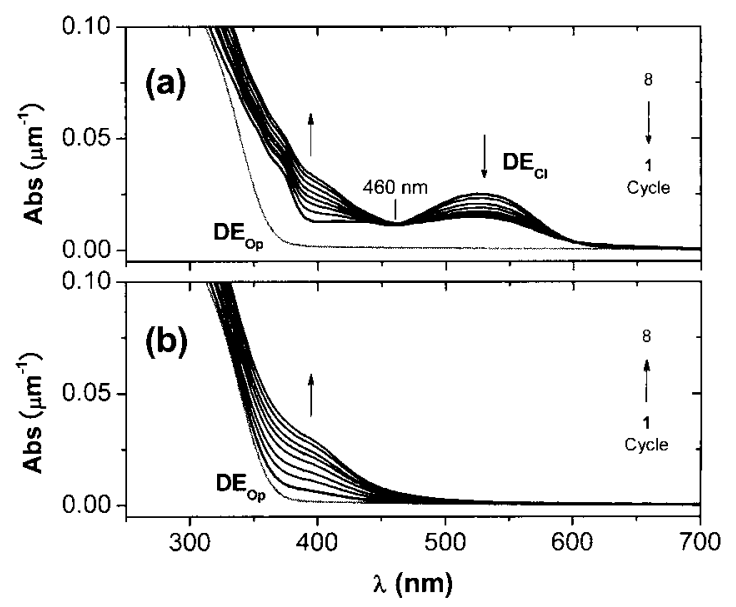

Figure 7. UV-vis absorption spectra of the PSt film containing $\mathbf{D E}_{\mathbf{O p}}$ at each alternating irradiation cycle with $\mathrm{EB}\left(100 \mu \mathrm{C} \mathrm{cm}^{-2}\right)$ and $>430 \mathrm{~nm}$ light for $1 \mathrm{~min}$; (a) after EB irradiation and (b) after visible light irradiation.

absorption maxima at around $370 \mathrm{~nm}$ cannot be assigned.

The polyaddition of BFP and DOX proceeds without remarkable cross-linking and the scission of the polymer main chains in the corresponding ether solution to give poly(BFP-alt-DOX) of $M_{\mathrm{n}}=5100$ with a dose of $3000 \mathrm{kGy}$ though most polymers are subjected to some damage by $\gamma$-rays and EB irradiation at doses of over $100 \mathrm{kGy}{ }^{9}$. This indicates 


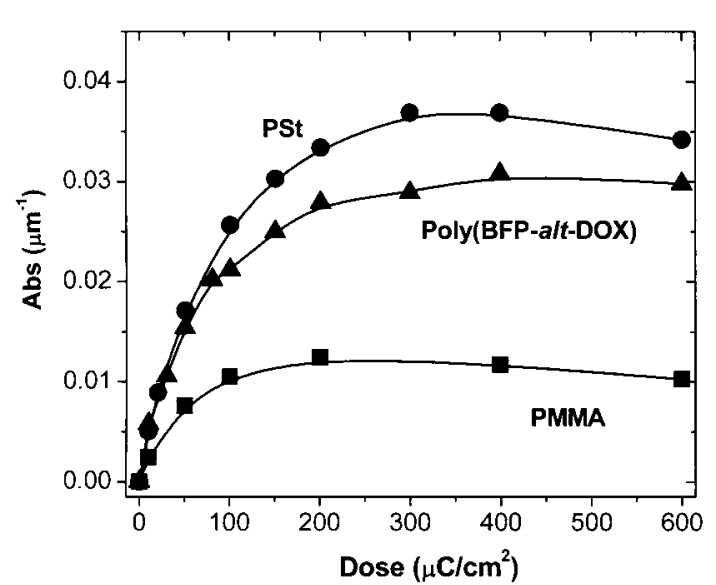

Figure 8. The plots of absorption intensity of the film containing $\mathbf{D E}_{\mathbf{O p}}$ at $510 \mathrm{~nm}$ as a function of

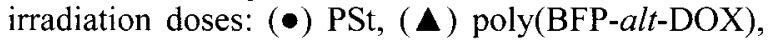
and (a) PMMA.

that poly(BFP-alt-DOX) has high radiation-resistance, and therefore it should work as a matrix polymer for EB-induced chromic systems. Upon EB-irradiation, the poly(BFP-alt-DOX) film containing colorless $\mathbf{D E}_{\mathbf{O}}$ exhibited red color with a dose of $100 \mu \mathrm{C} \mathrm{cm}^{-2}$. The new band at $\lambda_{\max }=510 \mathrm{~nm}$ assigned to the red-colored $\mathbf{D E}_{\mathbf{C l}}$, transformed from $\mathbf{D E} \mathbf{E}_{\mathbf{O p}}$ via a cyclization reaction, by comparing the new band with that obtained by $\gamma$-rays and photo-induced reactions. ${ }^{1 \mathrm{f}, 4 \mathrm{c}, 15}$ The formation of $\mathbf{D E} \mathbf{E l}_{\mathrm{Cl}}$, therefore, should be expressed by the cyclization reaction of $\mathbf{D E}_{\mathrm{Op}}$ in the poly(BFP-alt-DOX) film in Scheme 6. The matrix effect of poly(BFP-alt-DOX) on the chromic reactions was compared with that of conventional polymers such as PSt and PMMA. Figure 8 shows plots of absorption intensity at $510 \mathrm{~nm}$ as a function of an irradiation dose. The absorbance attributing to the formation of $\mathbf{D E}_{\mathbf{C}}$ was gradually increased with increasing irradiation doses and then saturated, except for PMMA. The EB-induced reaction in the poly(BFP-alt-DOX) film containing $\mathbf{D E}_{\mathbf{O p}}$ exhibited a few times higher coloration efficiency than that in the PMMA film.

Figure 9 shows relative absorption intensity of the films containing $\mathbf{D E}_{\mathbf{O}_{\mathbf{p}}}$ in poly(BFP-alt-DOX), PMMA, and PSt at $510 \mathrm{~nm}$ after EB-irradiation at each EB/photo cycle (up to 9). The relative intensity of the colored form in the poly(BFP-alt-DOX) matrix almost kept constant even after 5 cycles, then gradually declined to $81 \%\left(0.015 \mu \mathrm{m}^{-1}\right)$ of the first cycle at 8 cycles. Although the PSt film containing $\mathbf{D E}_{\text {Op }}$ exhibited a high EB-induced coloration efficiency at the first cycle, the relative intensity of the PSt film containing $\mathbf{D E}_{\mathbf{O}}$ at $510 \mathrm{~nm}$ decreased linearly to $80 \%$ of the first cycle with 3 cycles. A similar result was obtained with the PMMA film. These results may account for the following two

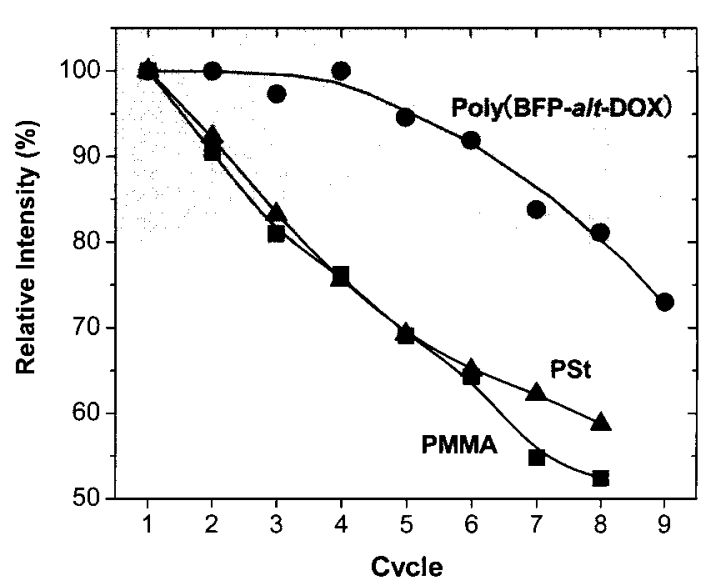

Figure 9. Relative absorption intensity of the films containing $\mathbf{D E}_{\mathbf{O p}}$ in poly(BFP-alt-DOX), PMMA, and PSt at $510 \mathrm{~nm}$ after EB-irradiation at each EB/photo cycle: $(\bullet)$ PSt, ( $\mathbf{A})$ poly(BFP-alt-DOX), and (ø) PMMA.

reasons: (1) the side reaction such as cross-linking and scission by EB-radiolysis was depressed by usage of high radiation-resistant poly(BFP-alt-DOX) as a matrix; (2) poly(BFP-alt-DOX) has higher electron density than PMMA does, and thereby showed higher generation efficiently of the activated (exited or ionized) spices of $\mathbf{D E}_{\mathbf{O} \mathbf{p}}$ than that in PMMA.

\section{3-3. EB-induced color imaging.}

The color imaging of $5 \mu \mathrm{m}$ square and $\mathrm{L} / \mathrm{S}$ patterns on the PMMA film containing SP-NO $(0.362 \mu \mathrm{m}$ thickness) was performed using EBDW with a $50 \mathrm{~nm}$ diameter beam, and was then evaluated using optical and confocal laser microscopy. Figure 10a shows the optical microscopic image of $5 \mu \mathrm{m}$ squares on the PMMA film containing SP-NO $\mathrm{NO}_{2}$ drawn with a dose of $100 \mu \mathrm{C} \mathrm{cm}^{-2}$. Dark regions (blue color), $5 \mu \mathrm{m}$ squares, correspond to the areas exposed with EB. Although the optical contrast was not high, the square patterns were observed with a dose of $100 \mu \mathrm{C} \mathrm{cm}$; unfortunately, the L/S patterns with nanoscale resolution were blurred. The square patterns faded again upon the thermal treatment. It is indicated that the SP-NO $\mathbf{O}_{2}$ molecules doped in the PMMA film reversibly transform between the colorless $\mathbf{S P}-\mathbf{N O}_{2}$ and colored $\mathbf{M C}-\mathbf{N O}_{2}$ isomers with $\mathrm{EB}$ and thermal reactions, respectively. Figures $10 \mathrm{~b}$ and $10 \mathrm{c}$ show the optical microscopic pictures of $5 \mu \mathrm{m}$ square and L/S patterns on the PMMA film containing SP-NO $\mathbf{N}_{2}$ drawn with a dose of $400 \mu \mathrm{C} \mathrm{cm}^{-2}$, in which a clear blue color image was observed compared by that with a dose of $100 \mu \mathrm{C} \mathrm{cm}^{-2}$. These patterns, however, were thermally irreversible. This is due to the formation of MC- $\mathbf{H}^{+}$with increasing irradiation dose. We can observe the better imaging patterns of the same films with confocal scanning laser micrograph since it provides a monochrome image with high resolution. 


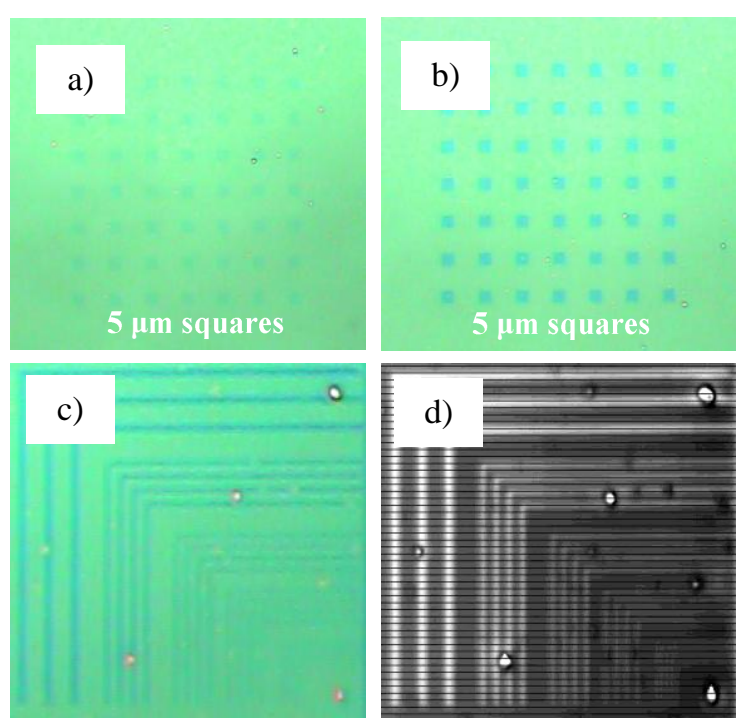

Figure 10. Top: Optical microscopic image of $5 \mu \mathrm{m}$ square patterns on the PMMA film containing $\mathbf{S P - N \mathbf { N } _ { 2 }}$ made with a dose of (a) $100 \mu \mathrm{C} \mathrm{cm}^{-2}$ and (b) $400 \mu \mathrm{C}$ $\mathrm{cm}^{-2}$. Bottom: (c) Optical microscopic image of a $\mathrm{L} / \mathrm{S}$ pattern with 100-1000 nm on the PMMA film containing SP-NO $\mathbf{N}_{2}$ made with a dose of $400 \mu \mathrm{C} \mathrm{cm}$, and (d) Confocal scanning laser micrograph of the same film.

As shown in Figure 10d, Clear L/S (black and white) patterns with the resolution of $200 \mathrm{~nm}$ can be observed.

Next, color imaging of the poly(BFP-alt-DOX) film containing $\mathbf{D E}_{\mathbf{O p}}(0.338 \mu \mathrm{m}$ thickness $)$ was examined using EBDW and observed using confocal scanning laser microscopy (Figure 11). The square and L/S patterns with optical differentiation between exposed (white) and unexposed (black) regions showed the clearest pattern of the film with a dose of $200 \mu \mathrm{C} \mathrm{cm}^{-2}$ with the resolutions of $200 \mathrm{~nm}$ and 100 $\mathrm{nm}$, respectively. Subsequently, the black and white patterns bleached upon the irradiation of visible light of $>430 \mathrm{~nm}$. Thus, the nanoscale color imaging by

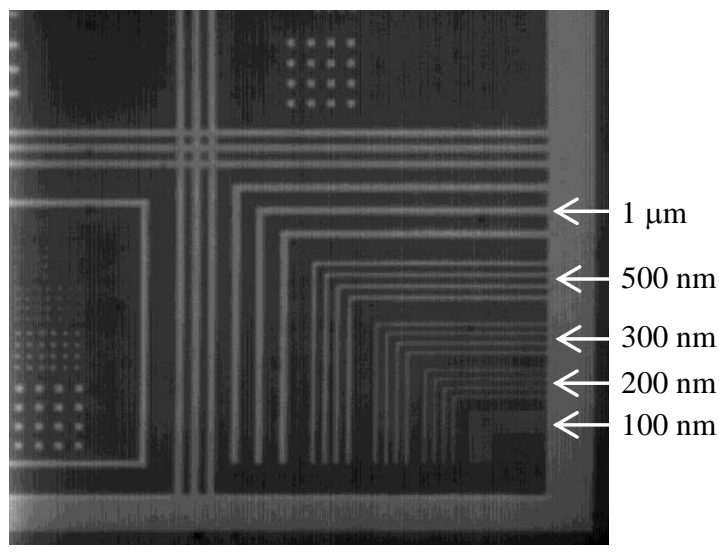

Figure 11. Confocal scanning laser micrograph of the poly(BFP-alt-DOX) film containing $\mathbf{D E}_{\mathbf{O p}}$, which was exposed using EBDW with a dose of $200 \mu \mathrm{C}$ $\mathrm{cm}^{-2}$. reversibly transformation between colorless $\mathbf{D E}_{\mathbf{O p}}$ and colored $\mathbf{D E}_{\mathbf{C I}}$ isomers can be achieved through EB and photochemical reactions, respectively.

\section{Conclusion}

The reversible color imaging on polymer films with a spiropyran $\left(\mathbf{S P}-\mathbf{N O}_{2}\right)$ or a diarylethene (DE) has been examined by electron-beam (EB) induced chromism combined with photo or thermal reverse reactions. The colorless $\mathbf{S P}-\mathbf{N O}_{2}$ in a poly(methyl methacrylate) (PMMA) film transformed into a red-colored zwitterionic merocyanine (MC-NO $\mathbf{N O}_{2}$, which subsequently converted to the original $\mathbf{S P}-\mathbf{N O}_{2}$ molecule via thermal treatment Six time repetition of the reaction cycle made the absorption intensity of MC-NO $\mathrm{N}_{2}$ decreased to $56 \%$ of the initial level. The decrease was attributed to the formation of the protonated $\mathbf{M C}$-form $\left(\mathbf{M C}-\mathbf{H}^{+}\right.$) via a side reaction of MC-NO $\mathbf{N}_{2}$ with an acid generated by EB-radiolysis of PMMA. Contrary to thermal treatment in the polymer films containing $\mathbf{S P}-\mathbf{N O}_{2}$, a photo reverse reaction could be applied for nanoscopic EB-induced color imaging using DE in the polymer films, where the thermally stable colored close-form of $\mathbf{D E}\left(\mathbf{D E}_{\mathbf{C l}}\right)$ obtained by an EB-induced reaction can be converted to the original colorless open-form $\left(\mathbf{D E}_{\mathbf{O p}}\right)$ via photoreaction. The matrix effect of poly(BFP-altDOX) was observed with good efficiency of color formation and higher fatigue resistance of DE than that in PSt and PMMA matrices. The color imaging of these films was performed by electron beam direct writing (EBDW) with a $50 \mathrm{~nm}$ diameter beam to form 100-1000 nm square and line/space (L/S) patterns. The color images of $5 \mu \mathrm{m}$ square patterns were produced in the PMMA film containing $\mathbf{S P}-\mathbf{N O}_{2}$ with a dose of $100 \mu \mathrm{C} \mathrm{cm}^{-2}$; the images could be faded upon thermal treatment. The poly(BFP-alt-DOX) film containing DE yielded clear color imaging of $100 \mathrm{~nm}$ $\mathrm{L} / \mathrm{S}$ patterns with a dose of $200 \mu \mathrm{C} \mathrm{cm} \mathrm{cm}^{-2}$. Subsequently, the patterns bleached upon the irradiation of visible light of $>430 \mathrm{~nm}$. It is noted that these reactions are the first example for reversible transformation of color imaging induced by EB radiation together with heat or light treatment.

\section{Acknowledgments}

The authors thank Mrs. S. Maniwa and $H$. Hanaya for making the facilities of the JAEA Electron Accelerator available to us. Technical support from Ms. K. Yuasa is also acknowledged.

\section{References}

(1) (a) H.-P.Brack, C. Padeste, M. Slaski, S. Alkan, H. H. Solak, J. Am. Chem. Soc. 2004, 126, 1004; (b) P. M. Mendes, S. Jacke, K. Critchley, J. Plaza, Y. Chen, K. Nikitin, R. E. Palmer, J. A. Preece, S. D. Evans, D. 
Fitzmaurice, Langmuir 2004, 20, 3766; (c) M. T. Russell, L. S. C. Pingree, M. C. Hersam, T. J. Marks, Langmuir 2006, 22, 6712; (d) Y. Wada, M. Katsumura, Y. Kojima, H. Kitahara, T. Iida, Jpn. J. Appl. Phys. 2001, 40, 1653; (e) S. Hosaka,; H. Sano, K. Itoh, H. Sone, Microelectron. Eng. 2006, 83 792; (f) M. Irie, Chem. Rev., 2000, 100, 1685; (g) G. Berkovic, V. Krongauz, V. Weiss, Chem. Rev., 2000, 100, 1741; (h) Y. Kaburagi, S. Tokita, M. Kaneko, Chem. Lett. 2003, 32, 888; (i) J. C. Scaiano, M. Laferriere, M. G. Ivan, G. N. Taylor, Macromolecules, 2003, 36, 6692 .

(2) Y. Maekawa, K. Yuasa, K. Enomoto, H. Matsushita, J. Kato, T. Yamashita, K. Ito, M. Yoshida, Chem. Mater., 2008, 20, 5320.

(3) (a) M. Farhataziz, A. J. Rodgers, Radiation Chemistry, Principles and Applications; VCH Publishers: New York, 1987; (b) Y.Tabata, Y. Ito, S. Tagawa, Handbook of Radiation Chemistry; Y. Tabata, Ed.; CRC Press: Boca Raton, 1991; (c) A. Hummel, In Advances in Radiation Chemistry; M. Burton, J. L. Magee, Eds.; John Wiley \& Sons: New York, 1974, Vol. 4, 1-102.

(4) (a) M. Irie, T. Fukaminato, T. Sasaki, N. Tamai, T. Kawai, Nature, 2002, 420, 759; (b) M. Irie, S. Kobatake, M. Horiuchi, Science, 2001, 291, 1769; (c) S. Kobatake, M. Irie, Bull. Chem. Soc. Jpn., 2004, 77, 195; (d) K. Uchida, A. Takata, M. Saito, A. Murakami, S. Nakamura, Adv. Funct. Mater., 2003, 13, 755; (e) C. Sanchez, B. Lebeau, F. Chaput, J. P. Boilot, $A d v$. Mater., 2003, 15, 1969.

(5) (a) K. Ichimura (Ed.); Development of Chromic Materials; CMC, Tokyo, 2000; (b) M. Irie (Ed.); Application of Functional Dyes; CMC, Tokyo, 2002.

(6) S. Kawata, Y. Kawata, Chem. Rev., 2000, 100, 1777.

(7) (a) T. Imai, N. Shida, T. Higuchi, K. Suga, T. Iida, F. Yokogawa, Jpn. J. Appl. Phys., 2001, 40, 1661; (b) M. Takeda, M. Furuki, T. Ishimoto, K. Kondo, M. Yamamoto, S. Kubota, Jpn. J. Appl. Phys., 2000, 39, 797; (c) Y. Wada, M. Katsumura, Y. Kojima, H.
Kitahara, T. Iida, Jpn. J. Appl. Phys., 2001, 40, 1653. (8) V. S. Ivanov, Radiation-chemistry of polymers; VSP 1992, Chapter 4.

(9) K. Enomoto, Y. Maekawa, Y. Katsumura, T. Miyazaki, M. Yoshida, H. Hamana, T. Narita, Macromolecules, 2005, 38, 9584.

(10) (a) S. Kawata, Y. Kawata, Chem. Rev., 2000, 100, 1777; (b) G. Berkovic, V. Krongauz, V. Weiss, Chem. Rev., 2000, 100, 1741.

(11) (a) K. Sumaru, M. Kameda, T. Kanamori, T. Shinbo, Macromolecules, 2004, 37, 4949; (b) I. Shimizu, H. Kokado, E. Inoue, Bull. Chem. Soc. Jpn., 1969, 42, 1726; (c) K. Yoda, T. Ohzeki, T. Yuzawa, H. Takahashi, Spectrochim. Acta., 1989, 45A, 855; (d) A. Fissi, O. Pieroni, N. Angelini, F. Lenci, Macromolecules, 1999, 32, 7116.

(12) (a) S. Tagawa, S. Nagahara, T. Iwamoto, M. Wakita, T. Kozawa, Y. Yamamoto, D. Werst, A. D. Trifunac, Proc. SPIE 2000, 3999, 204; (b) S-Y. Moon, Y. Maekawa, M. Yoshida, Chem. Lett. 2001, 408; (c) K. Enomoto, Y. Maekawa, S-Y. Moon, J. Shimoyama, K. Goto, T. Narita, M. Yoshida, J. Vac. Sci. Technol. B, 2006, 24, 2337.

(13) (a) M. Yanagita, I. Aoki, S. Tokita, Bull. Chem. Soc. Jpn., 1997, 70, 2757; (b) S. Tokita, K. Nagahama, F. Watanabe, J. Photopolym. Sci. Technol., 2000, 13, 187; (c) S. Tokita, F. Watanabe, K. Hashimoto, T. Tachikawa, J. Photopolym. Sci. Technol., 2001, 14, 221; (d) M. Hojo, T. Ueda, M. Yamasaki, A. Inoue, S. Tokita, M. Yanagita, Bull. Chem. Soc. Jpn., 2002, 75, 1569; (e) T. Tachikawa, M. Naito, J. Photopolym. Sci. Technol., 2004, 17, 81.

(14) (a) G. Ramanan, J. Phys. Chem., 1976, 80, 1553; (b) L. K. M. Kiminkinen, L. C. Zeller, H. I. Kenttamma, J. Chem. Soc., Chem. Commun., 1992, 466.

(15) (a) S. Irie, M.-S. Kim, T. Kawai, M. Irie, Bull. Chem. Soc. Jpn., 2004, 77, 1037; (b) S. Irie, M. Irie, Bull. Chem. Soc. Jpn., 2002, 75, 2071; (c) S. Irie, M. Irie, Bull. Chem. Soc. Jpn., 2000, 73, 2385; (d) S. Irie, M. Irie, Mol. Cryst. and Liq. Cryst., 2000, 345, 179. 